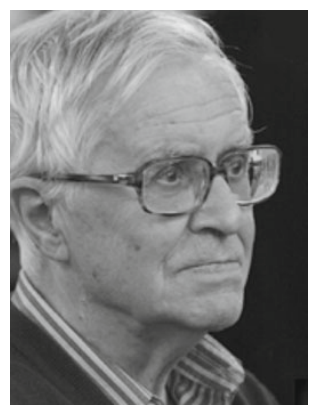

Keywords: architecture and mathematics, Staale Sinding-

Larsen
Conference Report

Architecture and Mathematics.

A seminar to celebrate Professor emeritus Staale Sinding-Larsen's 80th birthday

Trondheim, Norway, 25 November 2009

Report by Eir Grytli

Faculty of Architecture and Fine Art

Norwegian University of Science and Technology

Trondheim, NORWAY

eir.grytli@ntnu.no

Trained as an art historian, Professor Staale Sinding-Larsen held the chair of architectural history at the Norwegian University of Science and Technology (NTNU, former NTH), from 1970 to 2000. During this period he also served for seven years as Director General of the Norwegian Institute in Rome. Despite his age, Professor Sinding-Larsen is still an active researcher and writer, with a continuing curiosity and open-mindedness towards the advantages of cross-disciplinary approaches to architectural research. On the occasion of his 80th anniversary, his colleagues at the Faculty of Architecture and Fine Art wished to honour him with a seminar focusing on one of the topics that is closest to Professor Sinding-Larsen's heart, namely the relationship between architecture and mathematics. In order to make the interdisciplinary research on the meeting-point between architecture and mathematics visible, the seminar was organized in co-operation between the Faculty of Architecture and Fine Art and the Department of Mathematical Sciences at NTNU.

Professor Knut Einar Larsen, the initiator and organizer of the seminar, opened the event. He emphasized the open-mindedness with which Staale Sinding-Larsen has always approached his own profession, art history, and how his curiosity had introduced new ways of understanding and assessing architecture, ways which still today influence the way architectural history is taught at NTNU.

The programme of the seminar was organized in two sections. The first section, Historical Reflections, presented research about how use of mathematical thought and methods (and particularly geometry) has influenced architectural design in the past. The second section, The Contemporary Scene, focused on how mathematics is used in contemporary architectural design, especially regarding the possibilities made available by computer design.

Sylvie Duvernoy opened the first session, speaking on the topic Roman Architecture and Greek Mathematics - a Case Study: Pompeii's Amphitheatre.

Sylvie Duvernoy trained as an architect in Paris, and earned a doctorate from the University of Florence in 1998. She is professor of architectural drawing at the University of Ferrara. 


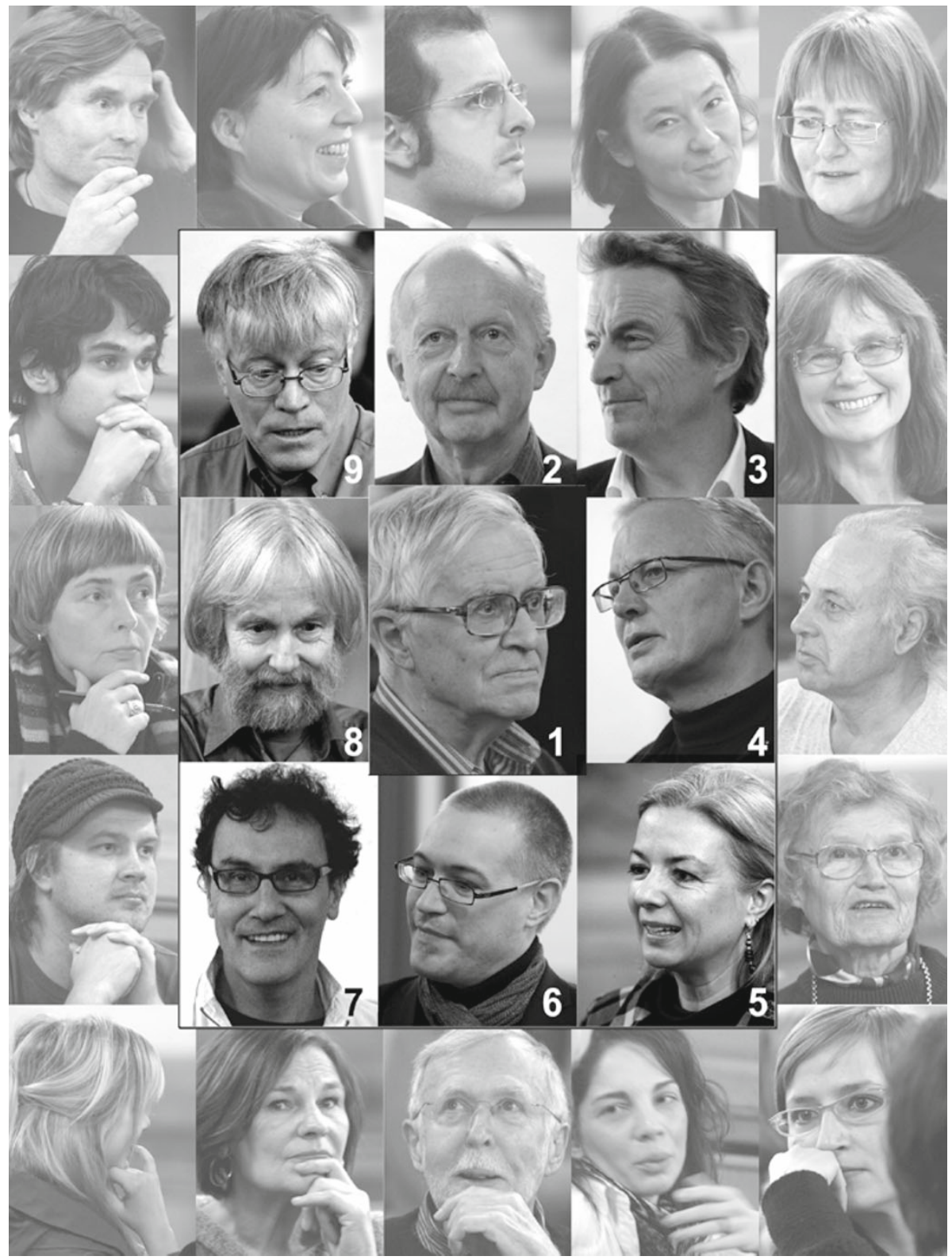

Participants at the seminar to celebrate Professor emeritus Staale Sinding-Larsen's 80th birthday: 1-Staale Sinding-Larsen; 2-Knut Einar Larsen; 3-Tore Haugen; 4Finn Hakonsen; 5-Sylvie Duvernoy ; 6- Fabian Scheurer; 7-Georg Glaeser; 8-Dag Nilsen; 9-Sverre Smalø. (photos by Georg Glaeser)

Duvernoy presented a case study on the amphitheatre in Pompeii. The study is a part of her comprehensive research of Roman amphitheatres, aimed at revealing the use of geometric diagrams in their designs through measured surveys and mathematical analysis of their curves. Around the beginning of the second century B.C the amphitheatre 
appeared as an architectural novelty in Roman culture, and was characterized by a closed elliptic shape that had never been previously adopted in architectural design. The period of time corresponds to the culmination of the Golden Age of Greek mathematics. It may be hypothesised that the necessity of designing a new building type provided theoretical mathematics with a successful field of direct and immediate experimentation. In her presentation, Duvernoy also called attention to how beauty is a related concept in architecture and in mathematics/geometry.

Dag Nilsen presented research entitled A Mathematical Game. Studying ratios of measures as a possible method in building archaeology? Dag Nilsen is trained as an architect, educated at NTNU (former NTH). Nilsen is associate professor at the Faculty of Architecture and Fine Art, NTNU, where he teaches architectural history and conservation.

When trying to reveal the history of a building, written sources are rarely sufficient to determine either its form and outline in earlier stages, or the intention of the builders. Nilsen maintains that through examining the building itself, it may be possible to develop a method to interpret specific questions encountered in building archaeology. By analyzing ratios of measures in two Norwegian medieval churches, it appears to be possible to explain previously unsolved problems of their design. In extensive studies of vernacular Norwegian architecture, Nilsen has also found indications that mathematical/geometrical tools have been used for design of building types not normally associated with professional designers.

Finn Hakonsen gave a talk on the subject Ornament and Geometry - The case of Tuse village church in Denmark. Finn Hakonsen is an architect trained at the Royal Academy of Fine Art in Copenhagen. His teaching and his writing are mainly based on the theories of the Tectonic Culture in Architecture.

The Tuse church at northern Seeland was built around the year 1200, in the Romanesque period of the country, and is one of more than a thousand medieval stone village churches in Denmark. The study presented is based on theories of architect Mogens Koch and its point of departure was the typical consecration crosses (hjulkors) found in the church, which appear as circular ornaments, usually associated with religious symbolism. The presentation launched the theory that these ornaments also embody a proportional system of the building. The study reveals correlations between the ornament and the proportions of the built structure. This leads to the question of whether the ornament, in addition to carrying religious meaning, also is a carrier of information for the aesthetical and structural design, a recipe for the entire building process.

Georg Glaeser opened the afternoon session with a talk entitled The Infinite Variety of Curved Surfaces. Georg Glaeser is a professor in mathematics and geometry at the University of Applied Arts in Vienna. He is also the author of several books about computer-based geometry. In the lecture, he presented the geometric programming system "Open Geometry". With the help of a C++ compiler, the user is able to create images and animations with arbitrary geometric context. The system provides a large library that makes it possible to carry out virtually any geometric task. It provides a pedagogical approach to understanding how curved surfaces are described as a function of mathematical formulas. His lecture was a fascinating demonstration of the possibilities of simulating curved surfaces using computer-aided programming tools, as well as illustrating how mathematics can also have an aesthetical dimension. The demonstration did not focus specifically on architectural structures, but showed the possibilities of 
modelling curved forms by mathematical formulas in a digital programming system which can be utilized in computer-aided architectural design.

Fabian Scheurer presented The realization of the impossible: Geometrical Challenges in Contemporary architectural Concepts. Fabian Scheurer is a computer scientist and partner of the company Designtoproduction in Zürich.

Today, mathematical and geometrical knowledge is of fundamental importance for the design and realization of complex, curved forms which are increasingly used in contemporary architecture design. Computer-aided technology has expanded the possibilities for architectural design and especially through the technology providing direct transfer from the design phase to production of components and elements, offering solutions for irregular shapes that otherwise could never have been realized. In his lecture, Scheurer also called attention to the challenges comprised between the seemingly infinite design possibilities and the complexity of the production and construction process, and how important it is that the computer tool be understood by the architects using it.

Finally, the central person of the day, Staale Sinding-Larsen, shared his Metaperspective on architecture and mathematics, based on his view of an object; he dealt not with an object in itself, but rather what can be done with it. This approach to understanding objects can be referred back to the object-oriented paradigm in the digital world: an object consists of a set of attributes and methods. Methods are groups of instructions with reference to the attributes. A model for understanding mathematical influence on architectural design based on this theory will be presented in his forthcoming publication, Borromini's Spire.

Due to the busy end-of term period, only a limited number of students of architecture were able to dedicate the whole day to the seminar. This was a pity, because knowledge about how mathematics has influenced architecture as a design tool - and continues to do so increasingly - is vital for both a historical understanding of the built environment and for future design processes. In his lecture, Fabian Scheurer emphasized the need for architects to understand digital tools in order to obtain optimal benefits in complex design tasks; such an understanding requires a deeper knowledge of mathematics than is normally taught in architecture schools.

Personally, not being an expert myself on mathematics in architecture, I found the seminar most interesting and relevant. The deeper understanding of how mathematics and geometry has been a creative force for the design of buildings through all times provides a language for "reading" historic built structures which adds to the historical knowledge about the creation of buildings. Maybe it also provides a better understanding of why contemporary changes and additions to historic buildings often look alien to the original, if the architect who planned the addition did not know the mathematical language used in the original building.

\section{About the reviewer}

Eir Grytli is an architect, with a Ph.D in vernacular development history (1993). She is Professor at the Faculty of Architecture and Fine Art, Norwegian University of Science and Technology (NTNU), Trondheim, Norway, where she teaches architectural history and building conservation. 